highly strenuous and time-consuming. The Bouguer anomaly using in situ observations can also be validated using such model results. Alternatively, gravimetric geoid can be generated over the Indian subcontinent using the VMM model. Validation of in situ/altimetry-derived Bouguer anomaly over the Indian land mass and its surroundings, and comparison with VMM-derived Bouguer gravity is a novel approach. Here the Moho depth could be estimated from the gravity data using the VMM model.

1. Nerem, R. S., Jekeli, C., Koblinisky, J. and Beckley, B. D., A preliminary evaluation of ocean topography from the TOPEX/POSEIDON mission. J. Geophys. Res., 1994, 99, 2456524583.

2. Sandwell, D. T. and Smith, S., Marine gravity anomaly from Geosat and ERS 1 satellite altimetry. J. Geophys. Res., 1997, 102(B5), 10039-10054

3. Majumdar, T. J., Mohanty, K. K., Mishra, D. C. and Arora, K., Gravity image generation over the Indian subcontinent using NGRI/EGM96 and ERS-1 altimeter data. Curr. Sci., 2001, 80(4), 542-554.

4. Majumdar, T. J. and Bhattacharyya, R., An atlas of very high resolution satellite geoid/gravity over the Indian offshore. SAC Technical Note No. SAC/RESIPA/MWRG/ESHD/TR-21/2004, p. 48.

5. Haxby, F., Karner, G. D., La Brecque, J. L. and Weissel, J. K., Digital images of combined oceanic and continental data sets and their use in tectonic studies. EOS Trans. Am. Geophys. Union, 1983, 64, 995-1004.

6. Ram Babu, H. V., Gravity image of India. Curr. Sci., 1999, 76, 1533-1535.

7. Eshagh, M., Bagherbandi, M. and Sjoberg, L. E., A combined global Moho model based on seismic and gravimetric data. Acta Geod. Geophys. Hung., 2011, 46(1), 25-38; doi:10.1556/ AGeod.46.2011.1.3.

8. Lemoine, F. G., et al., The development of the joint NASA GSFC and the National Imagery and Mapping Agency (NIMA) Geopotential model EGM96. NASA/GSFC Publ. No. NASA/TP-1998206861, 1998

9. Mahadevan, T. M., Deep continental structure of India: a review. Mem. Geol. Soc. India, 1994, 28, 569

10. NGRI Map Series, Gravity Map Series of India (1:5 million). National Geophysical Research Institute, Hyderabad, 1978, 1 st edn.

11. Verma, R. K. and Subrahmanyam, C., Gravity anomalies and the Indian lithosphere: review and analysis of existing gravity data. Tectonophysics, 1984, 105(1-4), 141-161.

12. Pal, S. K., Narayan, S., Majumdar, T. J. and Kumar, U., Structural mapping over the $85^{\circ} \mathrm{E}$ ridge and surroundings using EIGEN6C4 high-resolution global combined gravity field model: an integrated approach. Mar. Geophys. Res., 2016, doi:10.1007/s11001-0169274-3.

13. Thybo, H. et al., Moho: 100 years after Andrija Mohorovičić. Tectonophysics, 2013, 609, 1-8.

14. Mechie, J. et al., The distribution of Moho depths beneath the Arabian plate and margins. Tectonophysics, 2013, 609, 234-249.

15. Bagherbandi, M., MohoIso: a MATLAB program to determine crustal thickness by an isostatic and a global gravitational model. Comput. Geosci., 2012, 44, 177-183.

16. Heiskanen, W. A. and Moritz, H., Physical Geodesy, W H Freeman and Co, San Francisco, USA, 1967, p. 364

17. Sjoberg, L. E., Solving Vening Meinesz-Moritz inverse problem in isostasy. Geophys. J. Int., 2009, 179(3), 1527-1536; doi:10.1111/j.1365-246X.2009.04397.x.
18. Pavlis, N. et al., An earth gravitational model to degree 2160: EGM08. Presented at the 2008 General Assembly of the European Geosciences Union, Vienna, Austria, 13-18 April 2008.

19. Rao, G. C. et al., Lithosphere structure and upper mantle characteristics below the Bay of Bengal. Geophys. J. Int., 2016, 206, 675-695.

ACKNOWLEDGEMENTS. I thank Prof. M. Bagherbandi (University of Gävle, Sweden) for help in generating the VMM modelled data over the Indian Plate. I also thank the editor/reviewers for their critical comments.

Received 22 October 2018; revised accepted 8 May 2019

doi: $10.18520 / \mathrm{cs} / \mathrm{v} 117 / \mathrm{i} 3 / 502-506$

\section{Geostationary satellite-based observations for ocean applications}

\section{Neeraj Agarwal*, Rashmi Sharma, Pradeep Thapliyal, Rishi Gangwar, Prateek Kumar and Raj Kumar}

Earth, Ocean, Atmosphere and Planetary Sciences Area, Space Applications Centre, Indian Space Research Organisation, Ahmedabad 380 015, India

The study presents assessment and potential oceanographic applications of sea-surface temperature (SST), ocean net shortwave radiation (SWR) and chlorophyll concentration (CC) observations obtained from various geostationary platforms. SST and SWR from imager on-board Indian National Satellite (INSAT3D) and CC from Global Ocean Color Imager (GOCI) on-board communication ocean and meteorological satellite (COMS) have been used in the analysis. Relative advantages of high temporal resolution obtained from the geostationary platform compared to polar orbiting platforms are demonstrated. Comparison of INSAT-3D SST with observations gives a correlation of 0.85 and RMSE of $0.81 \mathrm{~K}$. These platforms definitely provide a highly reliable source of continuous observations, which is useful in monitoring dynamic oceanic features such as thermal fronts, chlorophyll blooms, air-sea exchange fluxes, etc. on diurnal to daily timescales.

Keywords: Chlorophyll concentration, geostationary satellites, INSAT-3D, sea-surface temperature, shortwave radiation.

OVER the next few years, a constellation of advanced meteorological geostationary (GEO) satellites (CGMS-46,

*For correspondence. (e-mail: neeraj@sac.isro.gov.in) 
$2018)^{1}$ having sensors with improved resolution (spectral, spatial and temporal) will open up many new possibilities for monitoring sub-daily dynamics of the land, oceans and atmosphere. This constellation in conjunction with data from moderate resolution low Earth orbit (LEO) satellites will help in studying wide range of variabilities and will aid in addressing many societal challenges pertaining to disaster, food security, marine dynamics, extreme events, etc. Different space agencies have a welllaid-out plan for continuity of geostationary missions with enhanced capability over the existing systems. Some of the current geostationary missions are Himawari-8/9, FY series by China, Korean satellite COMS, Meteosat, GOES and INSAT series (http://www. wmo.int/pages/prog/sat/satellitestatus.php). Although the primary mission of GEO satellites is to support operational meteorological services, they do offer opportunities for non-meteorological applications as well, e.g. ocean ${ }^{2,3}$, land $^{4}$ and sea-ice mapping ${ }^{5}$. As far as oceans are concerned, satellites in LEO have necessarily been the primary tool for monitoring the broader environment albeit with low temporal resolution. It is expected that in the coming years, measurements from GEO sensors can enhance and complement/supplement the LEO-based observations.

One of the most important applications from geostationary platforms is estimation of sea-surface temperature (SST) at fine temporal intervals, typically better than $30 \mathrm{~min}$, which provides information on its diurnal variations as well as obtaining daily cloud-free composite SST compared to selected time intervals from polar satellites. The high spatio-temporal resolution SST is useful in the determination of thermal fronts, which is an important parameter for finding the potential fishing zones, delineating upwelling zones and eddy activity ${ }^{6}$, and for estimating diurnal heating/cooling of the ocean surface waters. Using the International Satellite Cloud Climatology Project (ISCCP) and Special Sensor Microwave Imager (SSM/I) data, Clayson and Weitlich ${ }^{7}$ found daily diurnal variation in SST to be of the order of $1^{\circ} \mathrm{C}$ in the northern Indian Ocean, western and eastern equatorial Pacific Ocean and some other coastal regions. The continuity of geostationary satellites providing SST estimates will also be helpful in assessing the regional climate change, especially over the tropical region dominated by convective processes.

Geostationary Ocean Color Imager (GOCI) is the first geostationary ocean colour satellite sensor on-board the Korean Communication, Ocean and Meteorological Satellite (COMS) which was launched in 2010 having eight spectral bands from blue to near-infrared wavelengths. A strong diurnal variation in biogeochemical, optical and biological parameters has been reported around Korean coastal waters ${ }^{8,9}$. GOCI data have proved to be extremely useful in monitoring harmful algal bloom in the East China Sea ${ }^{10}$. Park et al. ${ }^{11}$ have studied diurnal variations in the surface current field for an eddy in the seas of Japan using GOCI-derived chlorophyll $a$ image data and found a quadratic relation between surface current and surface wind at sub-daily scale.

The shortwave radiative flux absorbed by the ocean surface plays an important role in the atmospheric and oceanic circulation through air-sea interaction, particularly over the warm pool region of the Indian Ocean ${ }^{12}$. The tropical oceans with SST usually greater than $28^{\circ} \mathrm{C}$, forms a major part of the largest warm pool on the earth. The variations of surface insolation over these warm pool regions are primarily due to the variations in cloudiness which are manifestations of deep convection ${ }^{13,14}$ and outgoing longwave radiation (OLR) is a good proxy for convection. Shinoda et al. ${ }^{13}$ proposed a simple empirical relationship, valid over warm pool oceanic regions, to estimate the daily averaged shortwave radiation (SWR) from the daily averaged OLR products obtained from the NOAA polar orbiting satellite. This has disadvantage as only a few orbits are available to obtain the daily averaged OLR, which is not a good representation of daily mean due to lack of adequate sampling and high diurnal variability of the cloud cover. To overcome this issue, Shahi et al. ${ }^{15}$ proposed the use of high temporal resolution data of OLR to improve the diurnal sampling in order to match that of the buoy SWR in computing daily averaged estimates. They demonstrated a significant improvement in the SWR using only daytime average of OLR obtained from half-hourly Meteosat observations, as night-time OLR variability is not representative of variations in the daily SWR. In the present study, we propose to use the algorithm of Shahi et al. ${ }^{15}$ for INSAT-3D data and evaluate its accuracy for operational applications.

Many previous studies are reported on usefulness of sub-daily observations from satellites for ocean applications $^{16-18}$. However, not many of them have provided an exhaustive account on what kind of variability is missed, if one uses data from polar satellites in such studies. In the present study, we have focused on three important ocean variables, viz. SST, SWR and chlorophyll, all from geostationary platforms. SST data over the Bay of Bengal from INSAT-3D have been used to assess the quality of the satellite and subsequently its use in identifying thermal fronts and diurnal variations. SWR from INSAT-3D also has been used to assess the quality. Another parameter used in the present analysis is chlorophyll $a$ data from GOCI, primarily with the objective to evaluate the subdaily variability in the seas of the Korean peninsula. The main focus of this study is to establish the importance of measuring these parameters from the geostationary platforms to circumvent the cloud problem in order to delineate features having high temporal variability.

SST from INSAT-3D was obtained from Meteorological and Oceanographic Satellite Data Archival Centre (MOSDAC, https://mosdac.gov.in), Space Applications Centre (SAC; ISRO) Ahmedabad. Mid-wave infrared 
$(\sim 3.8 \mu \mathrm{m})$ and split-window thermal infrared channels $(10.5-12.5 \mu \mathrm{m})$ were used to retrieve the SST product ${ }^{19}$. Table 1 provide details of various channels of INSAT-3D Imager and their Noise Equivalent Delta Temperature $(\mathrm{NE} \Delta \mathrm{T})$. The native horizontal resolution of the data is $4 \mathrm{~km}$, while the temporal resolution is every $30 \mathrm{~min}$. We have used the half-hourly images of 90 days starting from 1 January 2018 for analysis. The data were gridded to a horizontal resolution of $5 \mathrm{~km} \times 5 \mathrm{~km}$. The study area included North Indian Ocean, spanning the Arabian Sea and the Bay of Bengal.

In order to assess the quality of INSAT-3D SST, daily data available from a group of high-resolution sea surface temperature (GHRSST) have been used in this study ${ }^{20}$. It is a merged SST product which includes SST from all the available microwave and infrared sensors. The Level-4 (L4) product is generated using various objective analysis techniques to produce gap-free SST maps over the global oceans. The SST product used here has been generated by Jet Propulsion Laboratory (JPL), USA using optimum interpolation approach on a global $0.011^{\circ}$ grid. This is version 4 multiscale ultrahigh resolution (MUR) product (hereafter referred to as GHRSSTMUR4), which has inputs from all possible sources of SST such as NASA Advanced microwave scanning radiometer-EOS (AMSRE), the Moderate resolution imaging spectroradiometer (MODIS) on the NASA aqua and terra platforms, the US Navy microwave WindSat radiometer and in situ SST observations from the NOAA iQuam project. All the input data undergo rigorous quality control (information on the analysis can be found at ftp.mariana.jpl.nasa.gov/mursst/ tmchin/docs/ATBD).

INSAT-3D-derived OLR was estimated from the halfhourly observations in the thermal infrared (TIR, 10.5$12.5 \mu \mathrm{m})$ and water vapour absorption (WV, 5.7-7.1 $\mu \mathrm{m})$ channels at spatial resolution of $5 \mathrm{~km}$, using the algorithm developed by Schmetz and Liu ${ }^{21}$. These half-hourly OLRs were subsequently used to derived daily SWR following Shahi et al. ${ }^{15}$.

Apart from satellite data, SST and SWR from moored ocean buoy in the Indian Ocean ${ }^{22}$ have been used for validating INSAT-3D-derived SST and SWR, and GHRSST measurements. Observations of temperature and salinity from the National Oceanographic Data Center (NODC) under Global Temperature and Salinity Profile

Table 1. INSAT-3D imager channels and other parameters

\begin{tabular}{lccc}
\hline $\begin{array}{l}\text { Channel } \\
\text { no. }\end{array}$ & $\begin{array}{c}\text { Spectrum } \\
(\mu \mathrm{m})\end{array}$ & $\begin{array}{c}\text { Resolution } \\
(\mathrm{km})\end{array}$ & $\begin{array}{c}\text { S/N or } \\
\mathrm{NE} \Delta \mathrm{T}(\mathrm{K})\end{array}$ \\
\hline 1 & $0.52-0.72$ & 1 & $150: 1$ \\
2 & $1.55-1.70$ & 1 & $150: 1$ \\
3 & $3.80-4.00$ & 4 & 0.27 \\
4 & $6.50-7.00$ & 8 & 0.18 \\
5 & $10.3-11.2$ & 4 & 0.10 \\
6 & $11.5-12.5$ & 4 & 0.25 \\
\hline
\end{tabular}

Program (GTSPP) that provide essential, sub-surface climate variables of temperature and salinity profile data have been used for validating the satellite observations of SST. These data were compiled using several in situ measurements, including expendable bathythermographs (XBTs), conductivity-temperature-depths (CTDs), drifters and ARGO floats.

Hourly observations of chlorophyll concentration from GOCI on-board COMS were downloaded from https:// oceancolor.gsfc.nasa.gov/data/goci/. These observations (version 2014.0) are available from morning 0900 hours until $1600 \mathrm{~h}$ local time in eight spectral bands in a region of $2500 \times 2500 \mathrm{~km}$ around the Korean peninsula. The native resolution of the data is $500 \mathrm{~m}$. For our analysis, the data have been re-gridded to a horizontal resolution of $4 \mathrm{~km} \times 4 \mathrm{~km}$. We have used data of three months from 1 January 2018 through 31 March 2018 in this study.

Now we present a brief description on the performance of SST from INSAT-3D and GHRSST for the Bay of Bengal. For this, surface observations (at $0 \mathrm{~m} \mathrm{depth}$ ) from NODC temperature profiles were used. Collocated data from GHRSST, INSAT-3D and NODC profiles were used and they accounted for nearly 332 observations during the three-month period. Figure 1 shows the scatter between GHRSST, INSAT-3D and NODC data. Figure 2 shows the location of observations used in the statistics. It can be seen that the spread in INSAT-3D SST is larger compared to GHRSST. The root mean square error (RMSE) for these data points is $0.6 \mathrm{~K}$ and $0.33 \mathrm{~K}$ for INSAT-3D and GHRSST respectively.

Figure 2 shows the RMSE plot between the INSAT-3D daily data and high GHRSST. The errors at most of the places are less than $0.6 \mathrm{~K}$, although there are some pockets where errors are as large as $\sim 1 \mathrm{~K}$.

The reason for superior quality of GHRSST dataset is due to the fact that it is obtained from a combination of

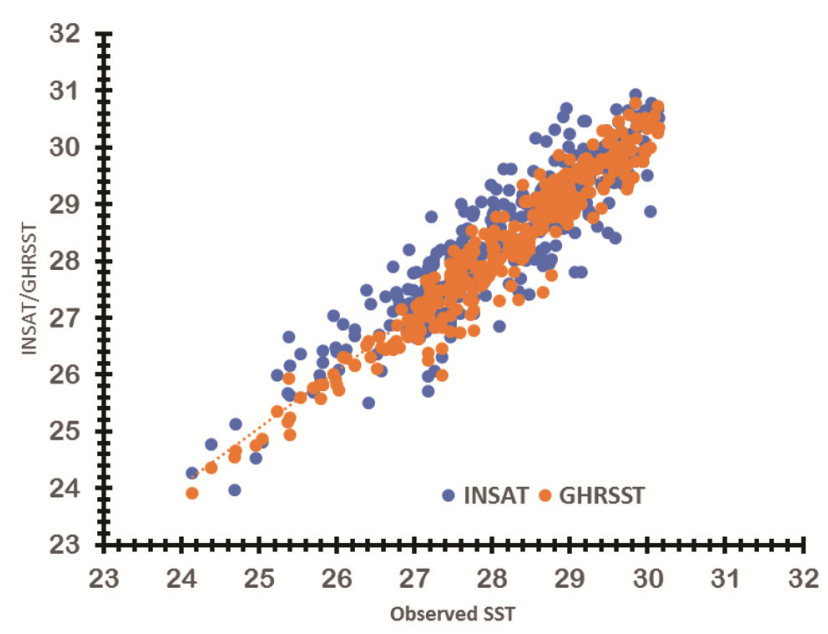

Figure 1. Scatter plot of observed sea-surface temperature (SST, source: NODC) with INSAT-3D SST (blue dots) and GHRSST (red dots) $(N=332)$. 


\section{RESEARCH COMMUNICATIONS}

best instruments available on polar as well as geostationary satellite ${ }^{20}$. These instruments in polar orbits have highly stable calibration with smaller uncertainties. INSAT-3D being in the geostationary platform is subjected to differential heating from various sides during different times of the day. One of the most important aspects is the midnight calibration problem in the geostationary platform, where sunlight directly enter into the camera assembly and heat up different various parts, which takes a lot of time to get stabilized ${ }^{23}$. Also, the availability of high spatial resolution of $1 \mathrm{~km}$ and microwave radiometer on-board polar satellites make it easier to estimate clear-sky radiances that leads to accurate SST estimation, which is not presently available from geostationary satellites.

Diurnal variations in SST can be as large as 1-2 K. These changes have a strong impact on air-sea interactions. Hence, it is necessary to resolve such changes for which the SST available from geostationary platforms plays an important role. Figure 3 shows time series of SST at buoy locations in the Bay of Bengal obtained from a mooring and from INSAT-3D at three-hourly time intervals. From the figure, it can be seen that there are large diurnal fluctuations in operational SST (left panel) compared to buoy SST. This may be attributed to the midnight calibration issues in thermal infrared observations of INSAT-3D. Small differences may also be attributed to differences in the skin (satellite) and bulk (in situ) $\mathrm{SST}^{24}$. In order to resolve these larger fluctuations, we have made use of one-dimensional variational (1DVAR) method for SST estimation. The numerical weather prediction (NWP) model SST forecast is used as a first guess to minimize the large fluctuations in the retrieved SST. A comparison of this SST product with buoy measurements has also been made (Figure 3 right panel). This 1D-VAR algorithm for SST retrieval is under implementation for operational use.

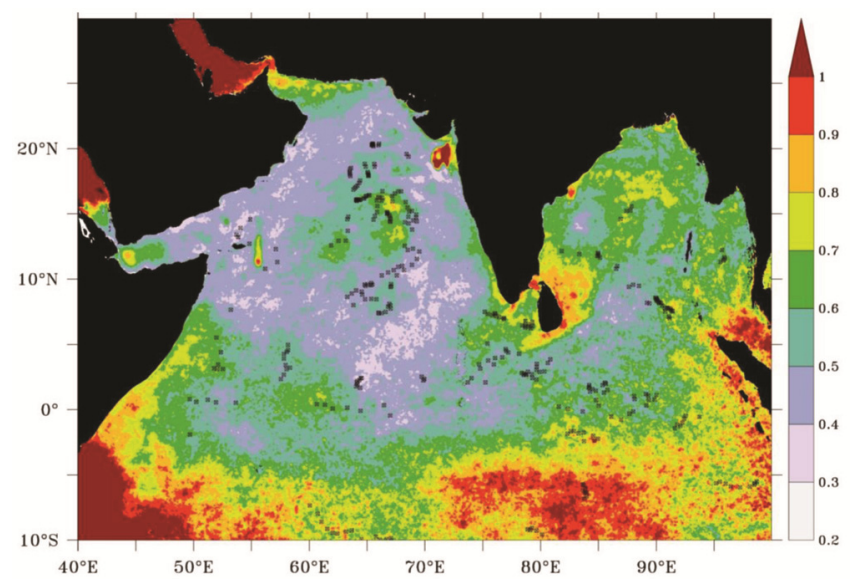

Figure 2. Root mean square error between INSAT-3D SST and GHRSST for January-March 2018. Black dots are locations of NODC observations which are used in Figure 1.
Comparison of INSAT-3D SST at a few buoy locations reveals that the data are able to capture diurnal variability reasonably well. Hence, SST from these platforms helps us understand the diurnal processes associated with SST variations.

The diurnal variation of SST in this region is $\sim 1 \mathrm{~K}$, and the satellite is able to capture these quite accurately with a correlation coefficient of $\sim 0.9$. Using a parametrization model, Clayson and Weitlich ${ }^{7}$ had reported diurnal warming values of the same order $(1 \mathrm{~K})$ in the northern Indian Ocean.

One can see that there are a lot of gaps in the time series of satellite observations. This is mainly due to the presence of clouds (Figure 3). The geostationary platform, because of its high temporal coverage, is able to provide many samples in a single day that are cloud-free. This is why one can get values at every 30 min interval and hence sub-daily variability can be captured easily. Visiting time of polar orbiting satellites is once in two days and hence changes associated at sub-daily scale cannot be resolved using such data. One can clearly see this in Figure 3, where GHRSST, which is daily averaged, misses the sub-daily scale variations. This was corroborated using INSAT-3D SST, where we computed the number of valid points (in percentage) available in each grid over a period of 90 days (January through March 2018) using two acquisitions per day, and in all the acquisitions available in a day. It can be easily seen from Figure $4 a$ that over a large portion of the Indian Ocean, percentage of valid points reaches near 100. Only a small region in the southeastern sector shows lesser valid points of the order of $50 \%$. This is attributed to the persistence clouds in this region. With two acquisitions per day (Figure $4 b$ ), barring the Arabian Sea and some parts of the Bay of Bengal, most of the regions have lesser valid data points, ranging between $20 \%$ and $70 \%$. This clearly indicates that in this part of the ocean, where there is persistent cloud cover most of the time during the year, it is mandatory to have SST measurements from the GEO platform. Next, it was imperative to observe daily averaged SST with two acquisitions and all acquisitions in a day. This is shown in Figure $5 a$ for 15 January 2018. One can clearly discern from the figure the importance of having SST from the GEO platform. Apart from data gaps (Figure $5 b$ ), the SST pattern appears to have a better depiction of small-scale features. The same small scale features and patterns appear to be very noisy and patchy in single acquisition as shown in Figure $5 a$.

Another important feature that we derive from SST is the thermal front. This is a sharp boundary between cold and warm water masses. Some fronts possess strong vertical motions on one or both sides, which may contribute to the vertical flux of nutrients and thus to higher phytoplankton biomass ${ }^{17}$. Due to the abundance of fish near the fronts, the study of variability of fronts is important for fishery industry. Fine Scale fronts may be 

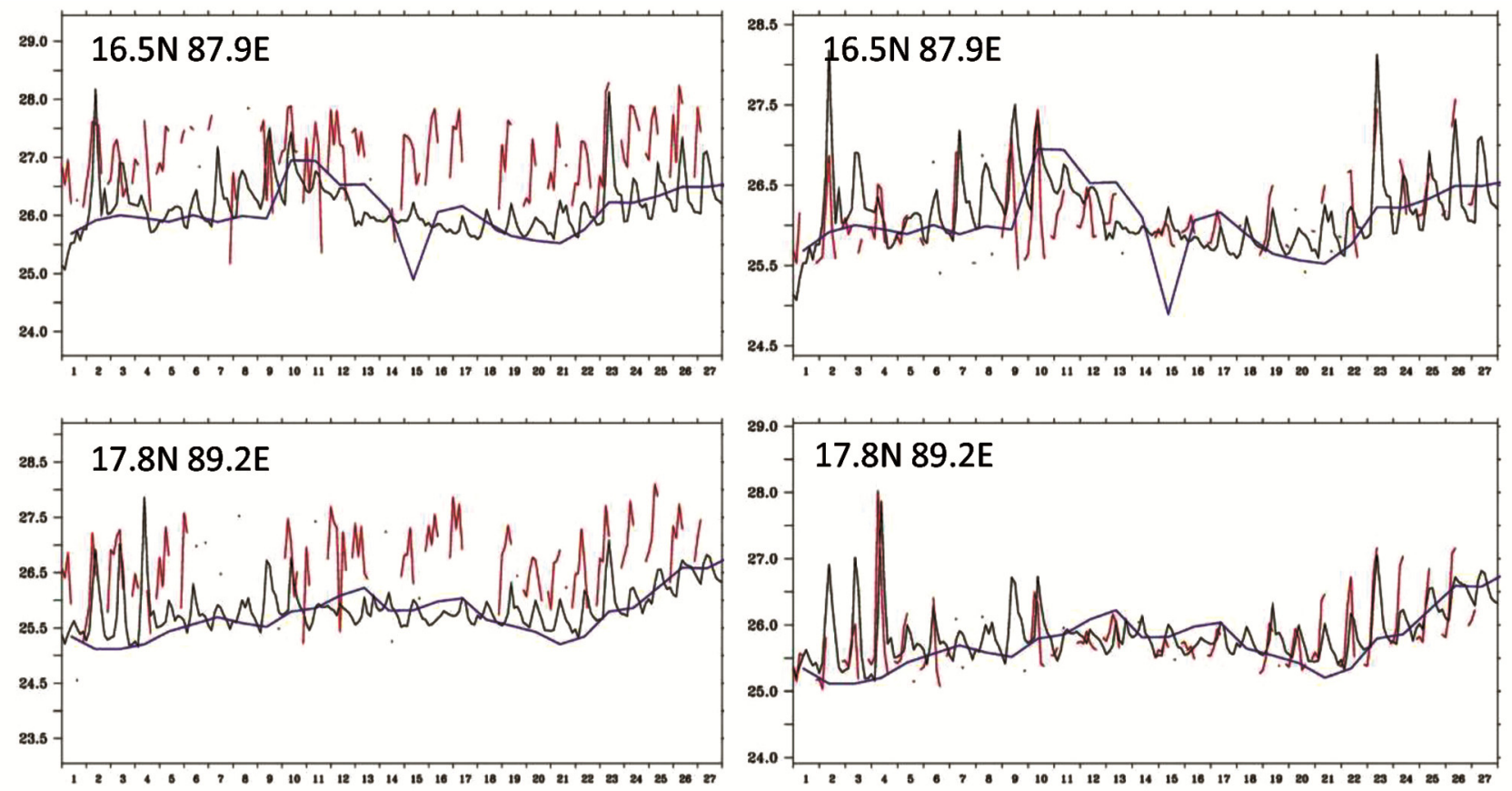

Figure 3. Time series of SST at two locations in the Bay of Bengal observed from buoy (black) along with the INSAT-3D (red) and GHRSST (blue). Left panel shows the operational product from INSAT-3D, while right panel shows the corrected product from INSAT$3 \mathrm{D}$.
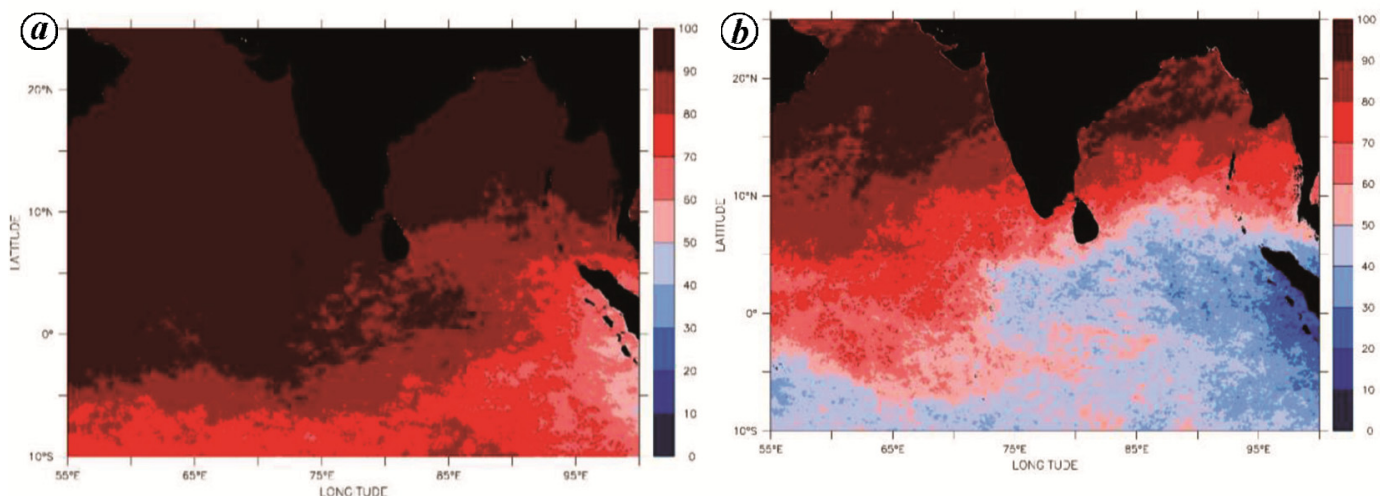

Figure 4. Number of INSAT-3D SST valid points in each grid in percentage obtained over a period of three months (January-March 2018) using (a) all acquisitions per day and (b) two acquisitions per day.
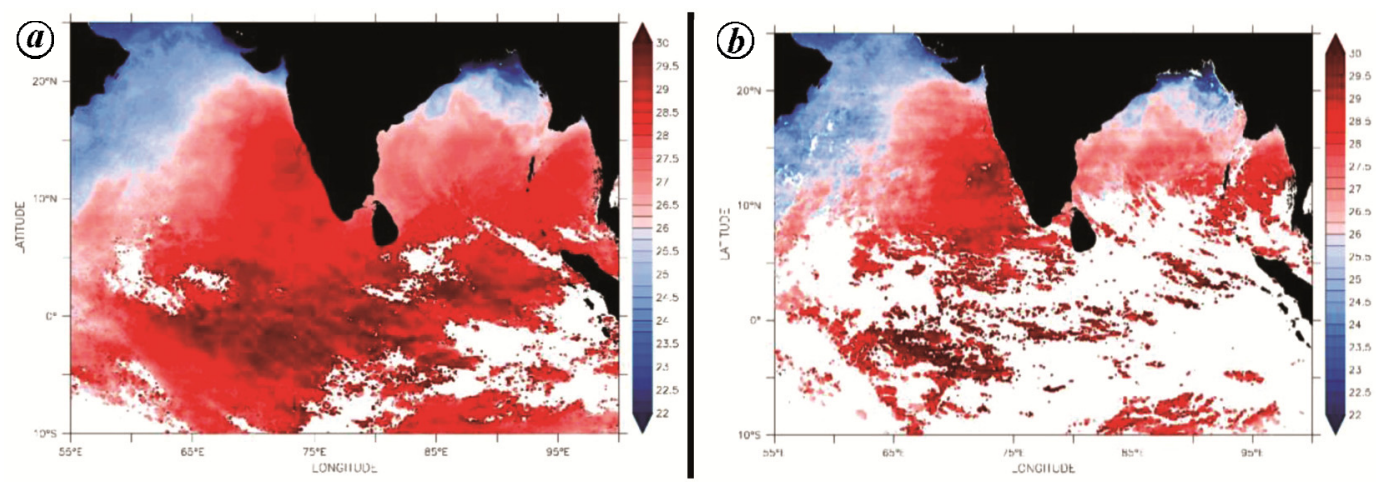

Figure 5. Daily averaged INSAT-3D SST obtained from $(\boldsymbol{a})$ all acquisitions and $(\boldsymbol{b})$ two acquisitions per day for 15 January 2018. 

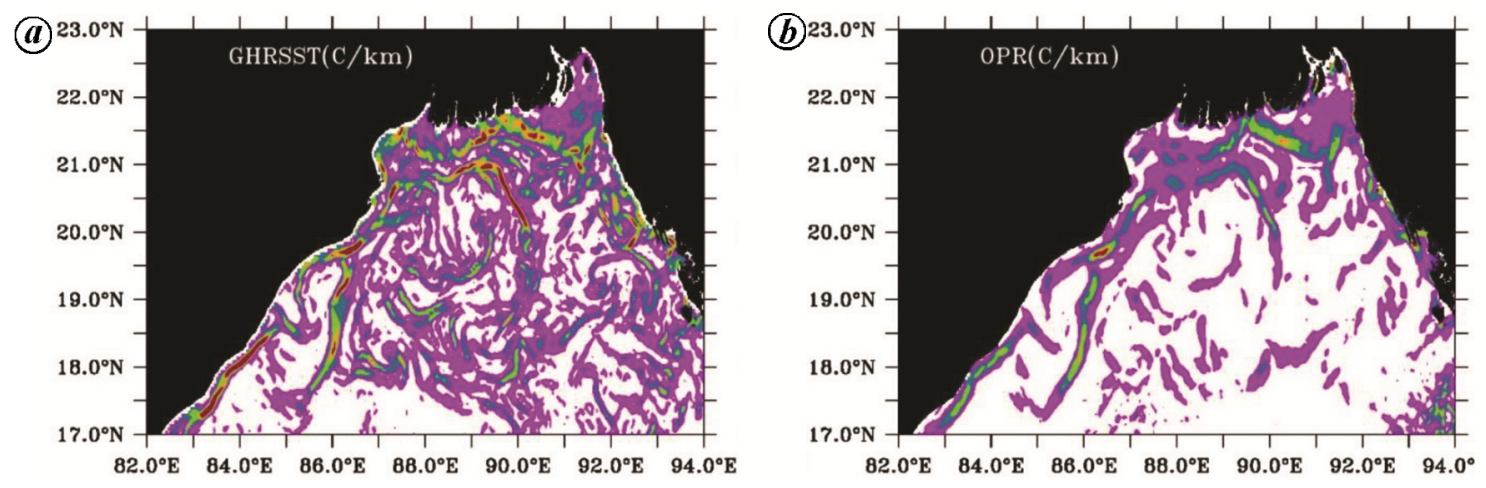

Figure 6. Daily averaged thermal fronts obtained from (a) GHRSST and (b) INSAT-3D SST for 4 January 2018.

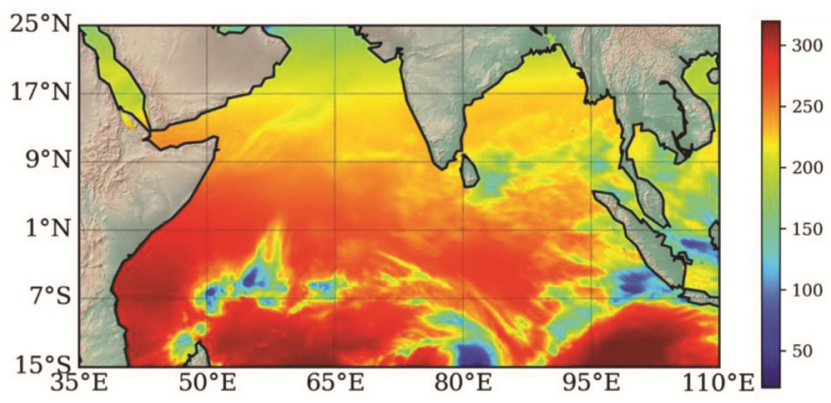

Figure 7. A sample daily SWR from INSAT-3D for 29 January 2018.

obtained using high-resolution data, which come from IR imagers. One of the drawbacks of the IR imager is that it cannot see through clouds and hence the region of interest needs continuous monitoring, which is only possible by geostationary satellites. SST from INSAT-3D is used to compute thermal fronts using spatial gradient magnitudes of SST and then finding the line of maxima (or minima) along these thermal gradients ${ }^{25}$. These lines are the thermal fronts. Figure 6 shows thermal fronts obtained from daily averaged INSAT-3D SST for 4 January 2018 in the north Bay of Bengal region. We have also plotted the fronts from GHRSST for the same day. One can clearly observe strong fronts in the region in both the dataset. These fronts are mainly generated due to strong air-sea interactions associated with freshwater discharge from the Ganges and the Brahmaputra. Thermal fronts from INSAT-3D data match qualitatively with those obtained from GHRSST; however, the magnitude is weak which may be attributed to the coarser spatial resolution of $4 \mathrm{~km}$ from INSAT-3D observations compared to $1 \mathrm{~km}$ from GHRSST products. This region is mainly covered by clouds during the southwest monsoon months (JuneSeptember). Hence acquiring images every $30 \mathrm{~min}$ provides a greater probability of getting a cloud-free picture of the ocean. On a clear day, such as those during winter, one can even track the movement of these fronts using INSAT-3D data.

The net SWR absorbed at the ocean surface is one of the main factors that influences air-sea interactions and ocean circulation. The high spatio-temporal resolution information of SWR in near real time needed for the Ocean Circulation Models is lacking over the vast tropical Indian Ocean. The accurate SWR information would result in improved assessment of heat balance over the warm-pool region $^{12}$, leading to significantly improved representation of the intra-annual oceanic surface processes and long-term surface variability. The diurnal variations in SST are driven by surface solar radiation that is modulated primarily by the presence of cloudiness.

Shahi et al. ${ }^{15}$ developed a methodology to estimate the net surface SWR over tropical oceans using half-hourly estimates of OLR from geostationary satellites. The SWR derived from Meteosat observations during 2002-09 over the Indian Ocean was validated with buoy-SWR, that shows an RMS error of $28.3 \mathrm{~W} \mathrm{~m}^{-2}$ compared to a value of $38.5 \mathrm{~W} \mathrm{~m}^{-2}$ obtained using the algorithm developed by Shinoda et $a{ }^{13}{ }^{13}$ for the same dataset. This was close to the value of $40.1 \mathrm{~W} \mathrm{~m}^{-2}$ obtained by Shinoda et al. ${ }^{13}$ from improved meteorology sensor system (IMET) mooring data by Weller and Anderson ${ }^{26}$. This large improvement of about $25 \%$ in RMSE is mainly attributed to the inclusion of half-hourly OLR data to represent better diurnal variability and further, the use of solar zenith angle in algorithm development. The estimated SWR was also compared with various primary sources of SWR estimates from international projects, and the accuracy of $28.3 \mathrm{Wm}^{-2}$ was found to be superior compared to the values of $32.7,37.5$ and $59.6 \mathrm{~W} \mathrm{~m}^{-2}$ obtained from the global energy and water cycle experiment-surface radiation budget V3.0 (GEWEX-SRB), International Satellite Cloud Climatology Project-Flux Data (ISCCP-FD), and National Center for Environmental Prediction (NCEP) reanalysis respectively, for the same dataset over the warm pool region of the Indian Ocean. This algorithm is operational for INSAT-3D and INSAT-3DR at SAC and India Meteorology Department, New Delhi. Figure 7 shows a sample of daily SWR derived from INSAT-3D.

The INSAT-3D SWR was validated for the period January-March 2018 using buoy observations in the Indian Ocean (Figure 8). The histogram in Figure 8 shows that 

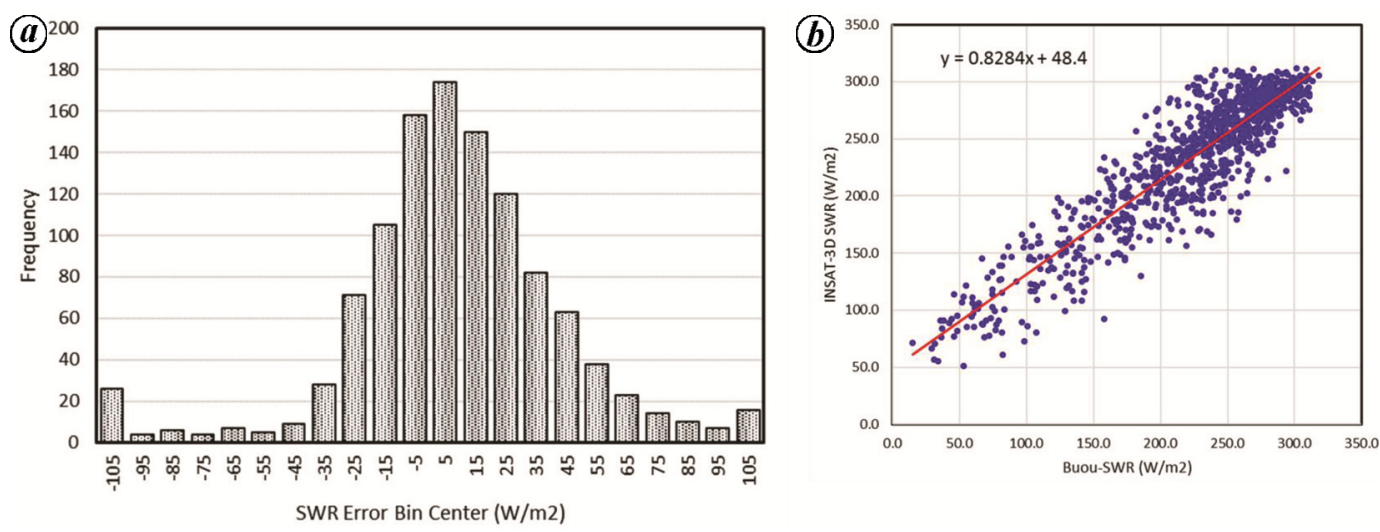

Figure 8. (a) Histogram of the SWR differences and (b) scatter plot between INSAT-3D SWR and buoy-SWR.
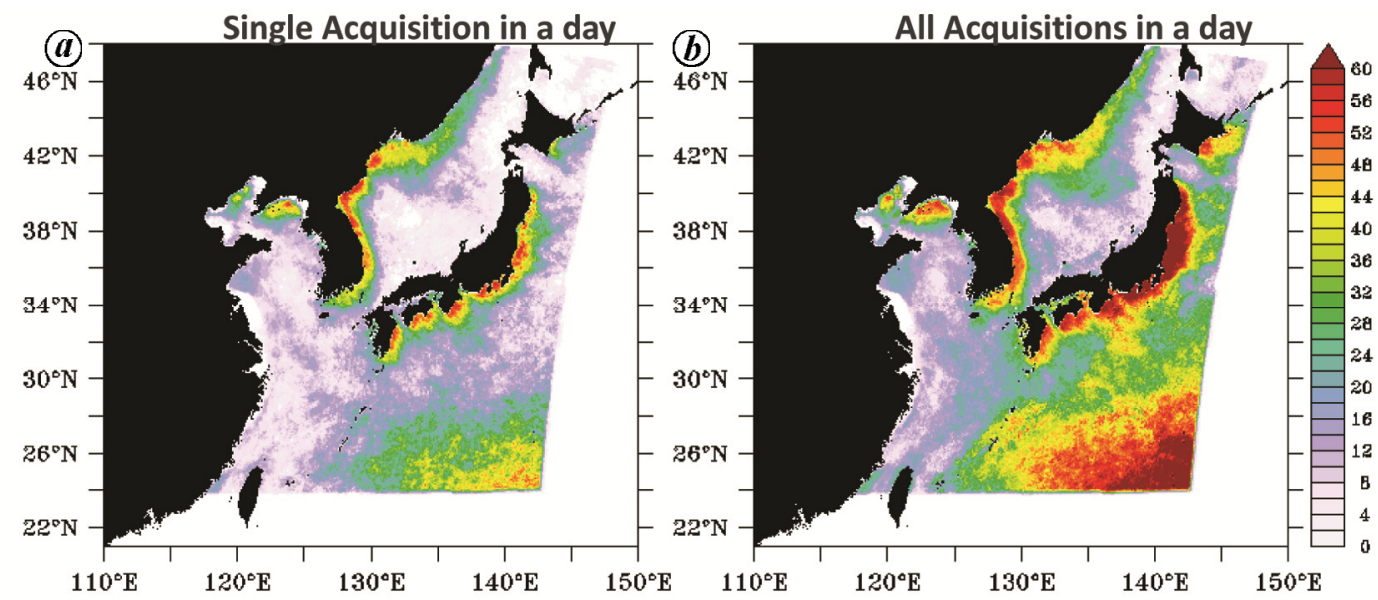

Figure 9. Percentage of valid data points of chlorophyll $a$ concentration $\left(\mathrm{mg} / \mathrm{m}^{3}\right)$ obtained from GOCI using $(\boldsymbol{a})$ a single acquisition in a day and (b) all acquisitions in a day for a 90-day (January-March 2018) period.

the differences mostly lie in the range -25 to $45 \mathrm{~W} \mathrm{~m}^{-2}$, with outliers having higher differences mainly due to geolocation error in the heterogeneous scene conditions and around the cloud edges. These outliers were rejected using a threshold of twice the standard deviation of SWR difference. The scatter plot in Figure 6 shows good correspondence between INSAT-3D SWR and the buoymeasured SWR. The bias and standard deviation of error in the INSAT-3D SWR are 9.5 and $26.4 \mathrm{~W} \mathrm{~m}^{-2}$ respectively, as validated with the buoy-measured SWR $(N=1052)$. The error statistics is similar to that obtained from the Meteosat satellite ${ }^{15}$. The daily SWR data from INSAT-3D are available at one day's delay, which is extremely important for the ocean modelling community.

Another important oceanic parameter that has wide applications and scientific value is the ocean chlorophyll concentration. This information is retrieved from the visible channels of the electromagnetic spectrum and hence it works only during daytime, when there is enough light available. Polar orbiting sensors such as the MODIS, SeaWiFS and Ocean Color Monitor on-board IRS-P4 and
Oceansat-2 provide one pass over a particular region in a day. Measurement of chlorophyll concentration is hampered by the presence of clouds, and hence it is necessary to get cloud-free scene from the satellites. This is possible only when we have multiple observations over the same region in a day. GOCI provides a good opportunity to get high-quality ocean colour data from a geostationary platform. One can get eight acquisitions in a day during daytime at an hourly interval from GOCI, which helps us map even the small-scale movement of the chlorophyll fronts. Figure 9 shows the percentage of observations obtained when a single acquisition of local noontime from GOCI is used to depict daily averaged chlorophyll concentration (similar to a polar orbiting platform), and when all acquisitions from GOCI in a day are used. The figure clearly shows that there are more observations that are valid when the temporal frequency is higher. In this region there are pockets where the percentage of valid points is very small $(<20)$, even in the case all acquisitions, implying that the region is predominantly covered by clouds. 

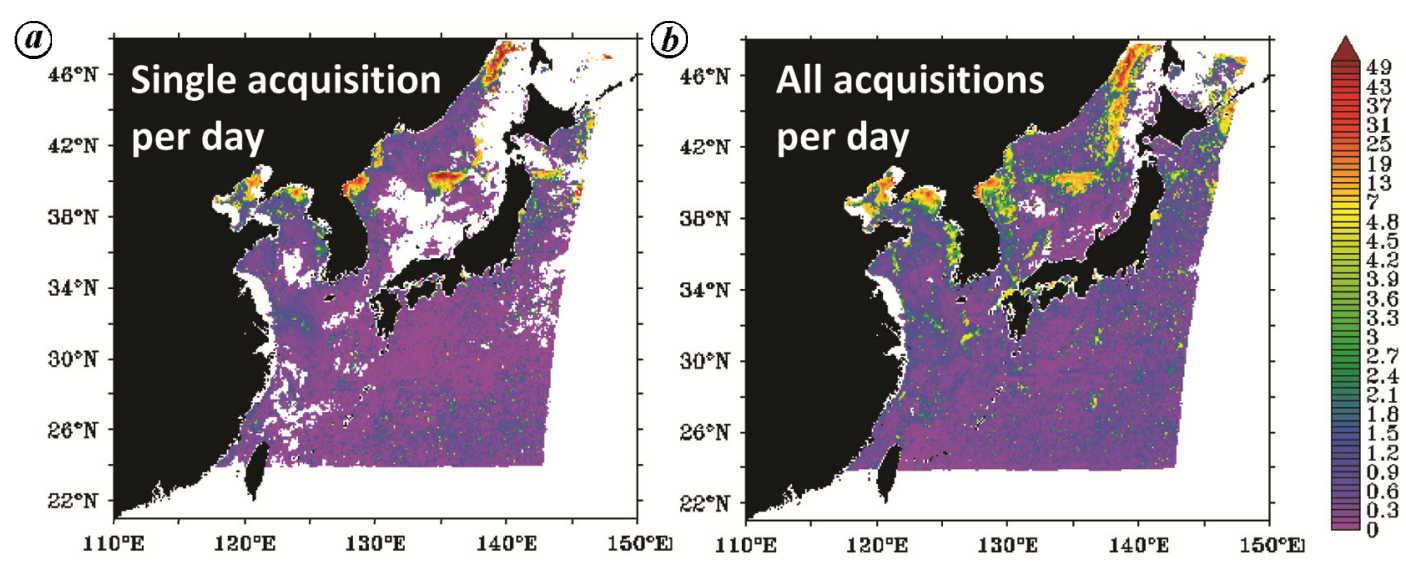

Figure 10. Variance of chlorophyll $a$ concentration over 90 days (January-March 2018) using (a) a single acquisition in a day and (b) all acquisitions in a day.

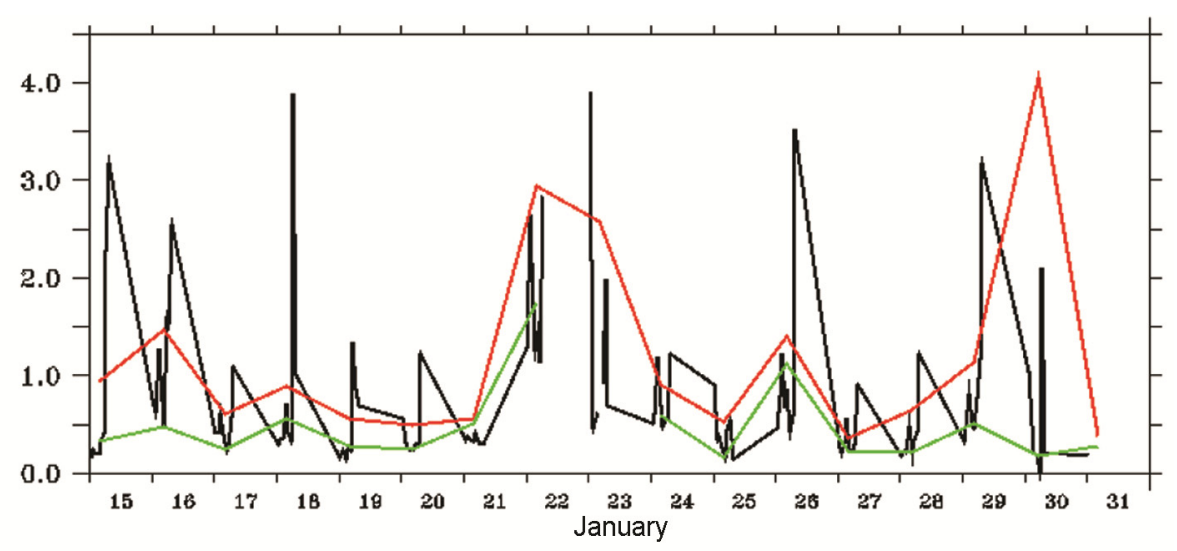

Figure 11. Time series of box-averaged chlorophyll $a$ concentration $\left(\mathrm{mg} / \mathrm{m}^{3}\right)$ from GOCI hourly observations (black line), all acquisitions averaged in a day (red line), single acquisition averaged in a day (green line).

Figure 10 shows the variance in chlorophyll concentration (CC) using single and all acquisitions in a day. $\mathrm{CC}$ is very high in the coastal regions and the satellite captures this well. It can be clearly seen that the image constructed using single acquisition has many gaps mainly due to lack of valid observations. Even in the regions where data are available, the fine-scale variability features are less compared to that in which all acquisitions are used.

The data sampled at high frequency from GOCI show large fluctuations within a day (Figure 11). Hence geostationary observations can be useful in those regions where there is high chlorophyll variability within a day. Such variabilities cannot be captured by polar orbiting platforms. Continuous monitoring of these features can provide useful input to the fishing industry to determine potential fishing zones and their movement.

Next, we studied a CC patch having a shorter lifetime of the order of few hours, for which observations from the geostationary platform are extremely useful. One can clearly see a case shown in Figure 12 for 1 January 2018, where there is a lot of variation in CC within $6 \mathrm{~h}$ in region. The generation and decay of $\mathrm{CC}$ taking place within a few hours are clearly observed. On any clear day, such hourly observations from these platforms can reveal biological activity and its subsequent impact on the dynamics of oceanic waters at sub-daily scale. This is a active area of research and researchers look forward to having hourly measurements of continuous global datasets from constellation of geostationary satellites. We look forward for ISRO's planned launch of GISAT, which will provide ocean measurements (SST and ocean colour) from a geostationary platform in the Indian region.

INSAT-3D, in its geostationary orbit, continuously monitors the Indian region at high spatio-temporal resolution. This gives an advantage to study the evolution and decay of small-scale features under clear sky conditions in the north Indian Ocean. A simple comparison of INSAT-3D-derived SST with that from NODC data gives a correlation of 0.85 and RMSE of $0.81 \mathrm{~K}$. Thermal gradients derived from INSAT-3D SST in the Arabian Sea, and the Bay of Bengal show patterns similar to those 

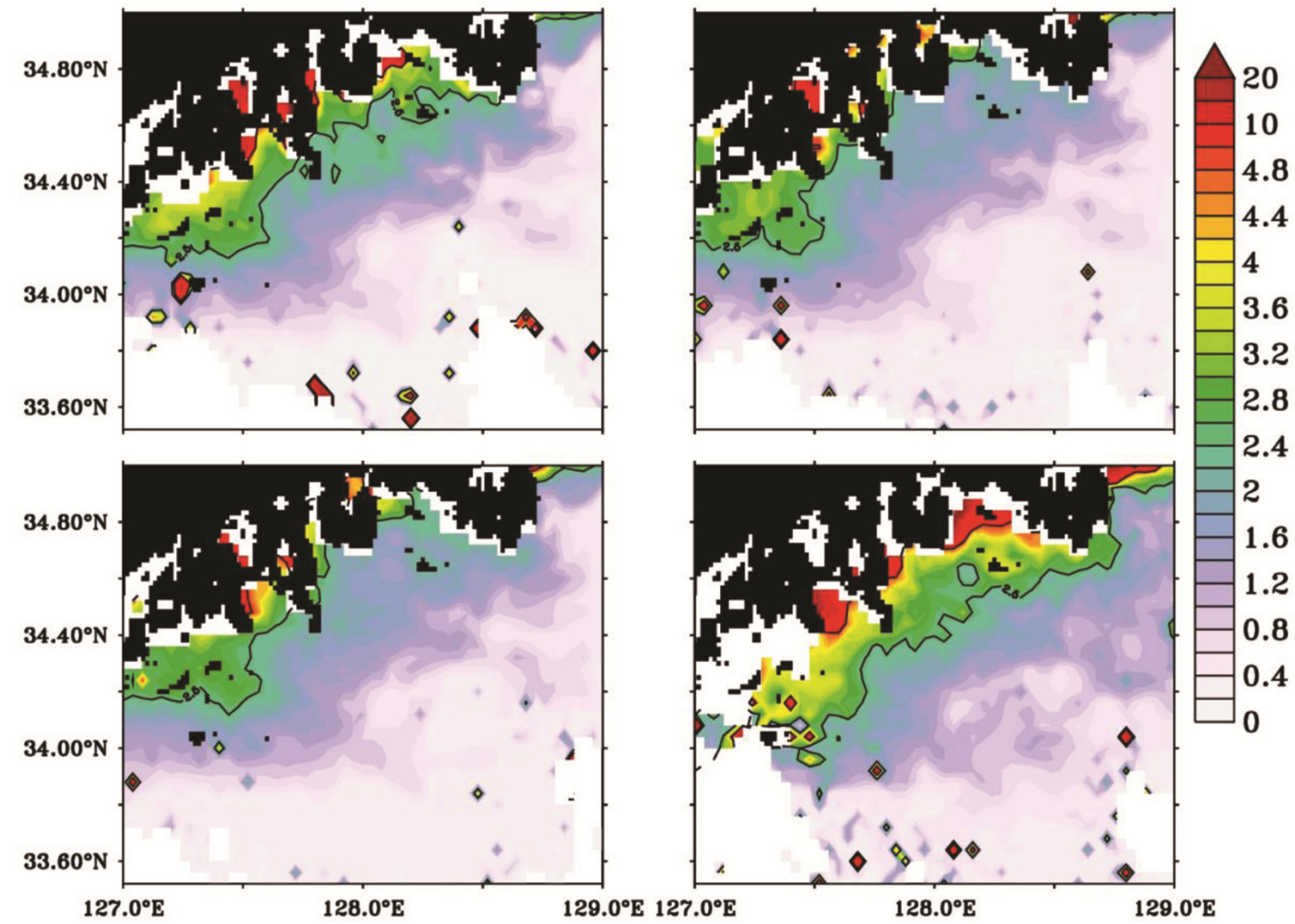

Figure 12. Variation of GOCI-derived chlorophyll $a$ concentration $\left(\mathrm{mg} / \mathrm{m}^{3}\right)$ within a day. The images are for $1 \mathrm{January}$ 2018, 00:27Z, 02:27Z, 04:27Z and 06:27Z.

derived from GHRSST, albeit with weaker magnitude. SST from INSAT-3D captures the observed diurnal variability, which is missing in the daily-averaged SST. Daily SWR derived from INSAT-3D compares extremely well with the buoy data having a standard deviation of error $\sim 26.4 \mathrm{~W} \mathrm{~m}^{-2}$. The important point is that this error is nearly the same in all the buoys, suggesting the robustness of the algorithm. Data from GOCI provided us an opportunity to study the variability in CC. It has been found that there is considerable variability at sub-daily scale. Standard deviation calculated with single observation per day from polar satellites, shows lesser variability as against multiple observations in a day from geostationary platforms. We have also observed that under cloudy conditions, least there is a probability of getting few observations during the day, which otherwise would likely be missed from polar platforms. Due to lack of ocean colour observations from geostationary platforms over a large area of global oceans, a detailed study on coupled biophysical processes at sub-daily scale is still far from reality. However, coordinated efforts from various space agencies under the umbrella of the Coordinated Group for Meteorological Satellites (CGMS) hold a great promise. One such mission to look forward is ISRO's GISAT, which will provide ocean colour and SST measurements from the same platform over the Indian Ocean region.
1. CGMS-46, Report of the 46th Plenary Session of the Coordination Group for Meteorological Satellites, CGMS-46, Bengaluru, 3-8 June 2018.

2. Murakami, H., Ocean color estimation by Himawari-8/AHI, 2016; doi:10.1117/12.2225422.

3. Kurihara, Y., Murakami, H. and Kachi, M., Sea surface temperature from the new Japanese geostationary meteorological Himawari-8 satellite. Geosphys. Res. Lett., 2015; doi:10.1002/2015 GL067159.

4. Nigam, R., Bhattacharya, B. K., Gunjal, K. R., Padmanabhan, N., and Patel, N. K., Formulation of time series vegetation index from Indian geostationary satellite and comparison with global product. J. Indian Soc. Remote Sensing, 2011, 40(1), 1-9.

5. Temimi, M., Romanov, P., Ghedira, H., Khanbilvardi, R. and Smith, K., Sea-ice monitoring over the Caspian Sea using geostationary satellite data. Int. J. Remote Sensing, 2011, 32(6), 15751593.

6. Legeckis, R. and LeBorgne, P., EUMETSAT geostationary satellite monitors the sea surface temperatures of the Atlantic and Indian Oceans since 2004. Environ. Res. Eng. Manage., 2009, 3(49), 4-9.

7. Clayson, C. A. and Weitlich, D., Variability of tropical diurnal sea surface temperature. J. Climate, 2007; https://doi.org/10.1175/ JCLI3999.1.

8. Wang, M., Son, S., Jiang, L. and Shi, W., Observations of ocean diurnal variations from the Korean geostationary ocean color imager (GOCI). Proc. SPIE 9111, Ocean Sensing and Monitoring VI, 911102, 2014; doi:10.1117/12.2053476.

9. Qi, L., Hu, C., Visser, P. M. and Ma, R., Diurnal changes of cyanobacteria blooms in Taihu Lake as derived from GOCI observations. Limnol. Oceanogr., 2018; doi:10.1002/lno.10802. 
10. Lou, X. and Chuanmin, H., Diurnal changes of a harmful algal bloom in the East China Sea: observations from GOCI. Remote Sensing Environ., 2014, 140, 562-572; https://doi.org/10.1016/ j.rse.2013.09.031.

11. Park, J.-E., Park, K.-A., Ullman, D. S., Cornillon, P. C. and Park, Young-Je, Observation of diurnal variations in mesoscale eddy sea-surface currents using GOCI data. Remote Sensing Lett., 2016; https://doi.org/10.1080/2150704X.2016.1219423,1131-1140.

12. Lukas, R., Observations of air-sea interaction in the western Pacific warm pool during WEPOCS. In Paper presented at the Western Pacific International Meeting and Workshop for TOGA COARE, Institut francais de Recherche scientifique pour le Developpement en Cooperation (ORSTOM), NOUMEA, New Caledonia, 1989.

13. Shinoda, T., Hendon, H. H. and Glick, J., Intraseasonal variability of surface fluxes and sea surface temperature in the tropical western Pacific and Indian Oceans. J. Climate, 1998, 11, 1685-1702.

14. Sengupta, D., Goswami, B. N. and Senan, R., Coherent intraseasonal oscillations of ocean and atmosphere during the Asian summer monsoon. Geophys. Res. Lett., 2001, 28, 4127-4130.

15. Shahi, N. R., Thapliyal, P. K., Sharma, R., Pal, P. K. and Sarkar, A., Estimation of net surface shortwave radiation over the tropical Indian Ocean using geostationary satellite observations: algorithm and validation. J. Geophys. Res., 2011, 116, C09031; doi:10.1029/ 2011JC007105.

16. Le Traon, P.-Y. et al., Use of satellite observations for operational oceanography: recent achievements and future prospects. J. Operational Oceanogr., 2015, 8(s12-s27); doi:10.1080/1755876X. 2015.1022050.

17. Minnett, P. J., Zhu, X., Hendee, J., Manfrino, C. and Berkelmans, R., Diurnal heating of shallow water-implications for satellite remote sensing of sea-surface temperature and monitoring coastal environments. In IEEE International Geoscience and Remote Sensing Symposium, IGARSS 2012, Munich, Germany, 22-27 July 2012

18. Stuart-Menteth, A. C., Robinson, I. S. and Challenor, P. G., A global study of diurnal warming using satellite-derived sea surface temperature. J. Geophys. Res. (Oceans), 2003, 108(C5), 3155; doi:10.1029/2002JC001534.

19. Mathur, A., Srinivasan, I., Gohil, B. S., Sarkar, A. and Agarwal, V. K., Development of sea surface temperature retrieval algorithm for INSAT-3D. In Remote Sensing and Modeling of the Atmosphere, Oceans, and Interactions, International Society for Optics and Photonics, Goa, India, December 2006, vol. 6404, p. 64040E.

20. Martin, M. et al., Group for High Resolution Sea Surface temperature (GHRSST) analysis fields inter-comparisons. Part 1: a GHRSST multi-product ensemble (GMPE). Deep Sea Res. II, 2012, 77-80, 21-30; doi.org/10.1016/j.dsr2.2012.04.013.

21. Schmetz, J. and Liu, Q., Outgoing longwave radiation and its diurnal variation at regional scales derived from Meteosat. J. Geophys. Res., 1988, 93(11), 192-204.

22. Venkatesan, R., Lix, J. K., Phanindra Reddy, A., Arul Muthiah, M. and Atmanand, M. A. Two decades of operating the Indian moored buoy network: significance and impact. J. Oper. Oceanogr., 2016, 9(1), 45-54.

23. Shukla, M. V., Thapliyal, P. K., Bisht, J. H., Mankad, K. N., Pal, P. K. and Navalgund, R. R., Intersatellite calibration of Kalpana thermal infrared channel using AIRS hyperspectral observations. IEEE Geosci. Remote Sensing Lett., 2012, 9(4), 687-689; doi:10.1109/LGRS.2011.2178813.

24. Casey, K. and Cornillon, P., A comparison of satellite and in situbased sea surface temperature climatologies. J. Climate, 1999, 12(6), 1848-1863.

25. Marra, J., Houghton, R. and Garside, C., Phytoplankton growth at the shelf-break front in the middle Atlantic bight. J. Mar. Res., 1990, 48(4), 851-868; doi:https://doi.org/10.1357/0022240907$\underline{84988665 .}$.
26. Weller, R. A. and Anderson, S. P., Surface meteorology and airsea fluxes in the western equatorial Pacific Warm Pool during the TOGA Coupled Ocean-Atmosphere Response Experiment. J. Climate, 1996, 9, 1959-1990; doi:10.1175/1520-0442(1996)009< 1959:SMAASF $>2.0 . \mathrm{CO} ; 2$.

ACKNOWLEDGEMENTS. We thank Shri D. K. Das, Director, Space Applications Centre (ISRO), Ahmedabad for his encouragement, and ESSO - Indian National Centre for Ocean Information Services, Hyderabad, for providing moored buoys data used in the study.

Received 22 November 2018; accepted 29 May 2019

doi: $10.18520 / \mathrm{cs} / \mathrm{v} 117 / \mathrm{i} 3 / 506-515$

\section{Non-native Neotropical nesting whitefly, Paraleyrodes minei Iaccarino on coconut palms in India and its co-existence with Bondar's nesting whitefly, Paraleyrodes bondari Peracchi}

\author{
Chandrika Mohan ${ }^{1, *}$, A. Josephrajkumar ${ }^{1}$, \\ Merin Babu ${ }^{1}$, Arya Krishna ${ }^{1}$, P. S. Prathibha ${ }^{2}$, \\ V. Krishnakumar ${ }^{1}$ and Vinayaka Hegde ${ }^{2}$ \\ ${ }^{1}$ ICAR-Central Plantation Crops Research Institute, Regional Station, \\ Kayamkulam 690 533, India \\ ${ }^{2}$ ICAR-Central Plantation Crops Research Institute, \\ Kasaragod 671 124, India
}

Field occurrence of the exotic neotropical nesting whitefly, Paraleyrodes minei Iaccarino in association with Bondar's nesting whitefly, Paraleyrodes bondari Peracchi on coconut leaflets is reported from Kerala, India. These coconut palms were previously infested by the rugose spiralling whitefly, Aleurodicus rugioperculatus Martin, which was reported from Kerala and Tamil Nadu during 2016. $P$. minei closely resembles $P$. bondari, but is devoid of the oblique grey bands on the wings and it constructs loosely woven, woolly wax nests. Female $P$. minei are white, but males are smoky grey. Cockhead-like male aedeagus with two thin appendixes projected downwards is the unique feature for species-level identification of $P$. minei. Detection of three non-native whiteflies of neotropical origin infesting coconut palms in India within a span of two years suggests their simultaneous introduction. Invasive potential of $P$. minei due to its polyphagous nature and short lifecycle calls upon strict policy frameworks in exchange of planting materials. Domestic quarantine should be strictly enforced in the country to avoid spread of this pest to other coconut-growing regions.

*For correspondence. (e-mail: cmcpcri@gmail.com) 